\title{
Cystic fibrosis presenting as kwashiorkor with florid skin rash
} Roderic J Phillips, Catherine M Crock, Michael J Dillon, Peter T Clayton, Arlene Curran,
John I Harper

\begin{abstract}
Two infants with a florid erythematous rash and generalised oedema, hypoalbuminaema, and anaemia were found to have cystic fibrosis. This rare presentation is associated with false negative sweat tests, delays in diagnosis, and a considerable mortality. It is proposed that this presentation represents a manifestation of kwashiorkor secondary to malabsorption. The recognition that these infants have kwashiorkor provides some insight into the pathogenesis and management of their illness.
\end{abstract}

(Arch Dis Child 1993; 69: 446-448)

In countries where routine neonatal screening for cystic fibrosis is not performed, this disease primarily presents as meconium ileus, failure to thrive, pulmonary disease, malabsorption, or rectal prolapse. Presentation of cystic fibrosis with a rash is very rare and has been associated with delays in diagnosis and a considerable mortality. ${ }^{1-4}$ We describe two infants born in the UK who presented with a rash and who were eventually found to have cystic fibrosis.

\section{Case reports}

PATIENT 1

A 3 month old white boy was referred to the Hospitals for Sick Children, London, for evaluation of rash, anaemia, and hypoalbuminaemia. He was born at term weighing $3300 \mathrm{~g}$ and was breast fed. By 2 weeks of age he was passing 10 to 20 loose, often bright green stools per day. An erythematous papular rash appeared on his buttocks and trunk and spread over the next several weeks to involve his whole body. At 2 months of age he was admitted to a local hospital because of pallor. Although described as appearing well nourished, he was found to have a haemoglobin concentration of $80 \mathrm{~g} / \mathrm{l}$ that subsequently fell to $60 \mathrm{~g} / 1$, albumin $12 \mathrm{~g} / 1$ (normal range 35-55), and zinc $6 \mu \mathrm{mol} / 1(11-24) . \mathrm{He}$ was treated with blood transfusions, intravenous albumin and antibiotics, and topical hydrocortisone. He continued to deteriorate and was transferred to the Hospitals for Sick Children.

On examination, he weighed $4.5 \mathrm{~kg}$ (25th centile) and was lethargic, with generalised oedema and a palpable liver edge $4 \mathrm{~cm}$ below the costal margin. Clearly demarcated, erythematous, scaly plaques up to $3 \mathrm{~cm}$ in diameter covered most of his body leaving only islands of normal skin (figure). Papules and areas of superficial desquamation were present on his palms and soles. His hair was sparse. Mucous membranes were unaffected.

Laboratory abnormalities included the following (normal range in parentheses): haemoglobin concentration $90 \mathrm{~g} / 1$ (95-135), reticulocytes $2 \cdot 2 \% \quad(0-2)$, platelet count $134 \times 10^{9}(150-400)$, prothrombin time 15.5 seconds $(10 \cdot 5-14 \cdot 5)$, kaolin partial thromboplastin time (KPTT) 51 seconds (30-45), aspartate transaminase $131 \mathrm{U} / \mathrm{l} \quad(20-60)$, albumin $22 \mathrm{~g} / \mathrm{l}(35-55)$, lactate $4.3 \mathrm{mmol} / \mathrm{l}$ $(0 \cdot 9-1 \cdot 8)$, zinc $9 \mu \mathrm{mol} / 1$ (11-24), copper 6 $\mu \mathrm{mol} / 1$ (13-27), iron $13 \mu \mathrm{mol} / \mathrm{l}$ (14-22), ferritin $3245 \mu \mathrm{g} / \mathrm{l}(7-150)$, and low concentrations of many plasma amino acids. A skin biopsy specimen showed a mild mononuclear, perivascular infiltrate. In some areas, this infiltrated the epidermis which showed a lack of a granular layer but was of normal thickness with no hyperkeratosis or parakeratosis. A liver biopsy specimen showed extensive fat infiltration, a mild inflammatory infiltrate around the portal tracts, normal bile ducts, and stainable iron. Bone marrow aspirate and trephine showed erythroid hypoplasia, vacuolated erythroblasts, some abnormal promyelocytes, and increased iron.

He had a stormy eight week hospital stay complicated by Staphylococcus aureus septicaemia and by cardiac failure. Improvement in the rash was observed over the first two weeks after zinc supplementation and transfusions of albumin and blood. Complete resolution of his rash occurred after changing his diet from breast milk to an elemental formula (Pregestimil, Bristol Myers). A diagnosis of cystic fibrosis was eventually reached when genetic analysis for cystic fibrosis mutations showed homozygous delta $\mathrm{F}_{508}$ deletions on chromosome 7 . When his skin had cleared, sweat sodium concentrations (mg of sweat in sample) were measured as 81 (179) and 86 (108) $\mathrm{mmol} / \mathrm{l}$ respectively on two tests $(>60$ $\mathrm{mmol} / \mathrm{l}$ is considered diagnostic of cystic fibrosis). After pancreatic enzyme replacement and vitamin supplements, his weight fell to below the third centile as his oedema and other presenting problems resolved. One year after discharge he continued to gain weight satisfactorily along the third centile. There was no recurrence of his symptoms nor evidence of chest disease.

PATIENT 2

A 5 month old white girl was referred to the Hospitals for Sick Children, London, for evaluation of rash, failure to thrive, and anaemia. She was born at term weighing $3400 \mathrm{~g}$ and was breast fed. Her stools were 

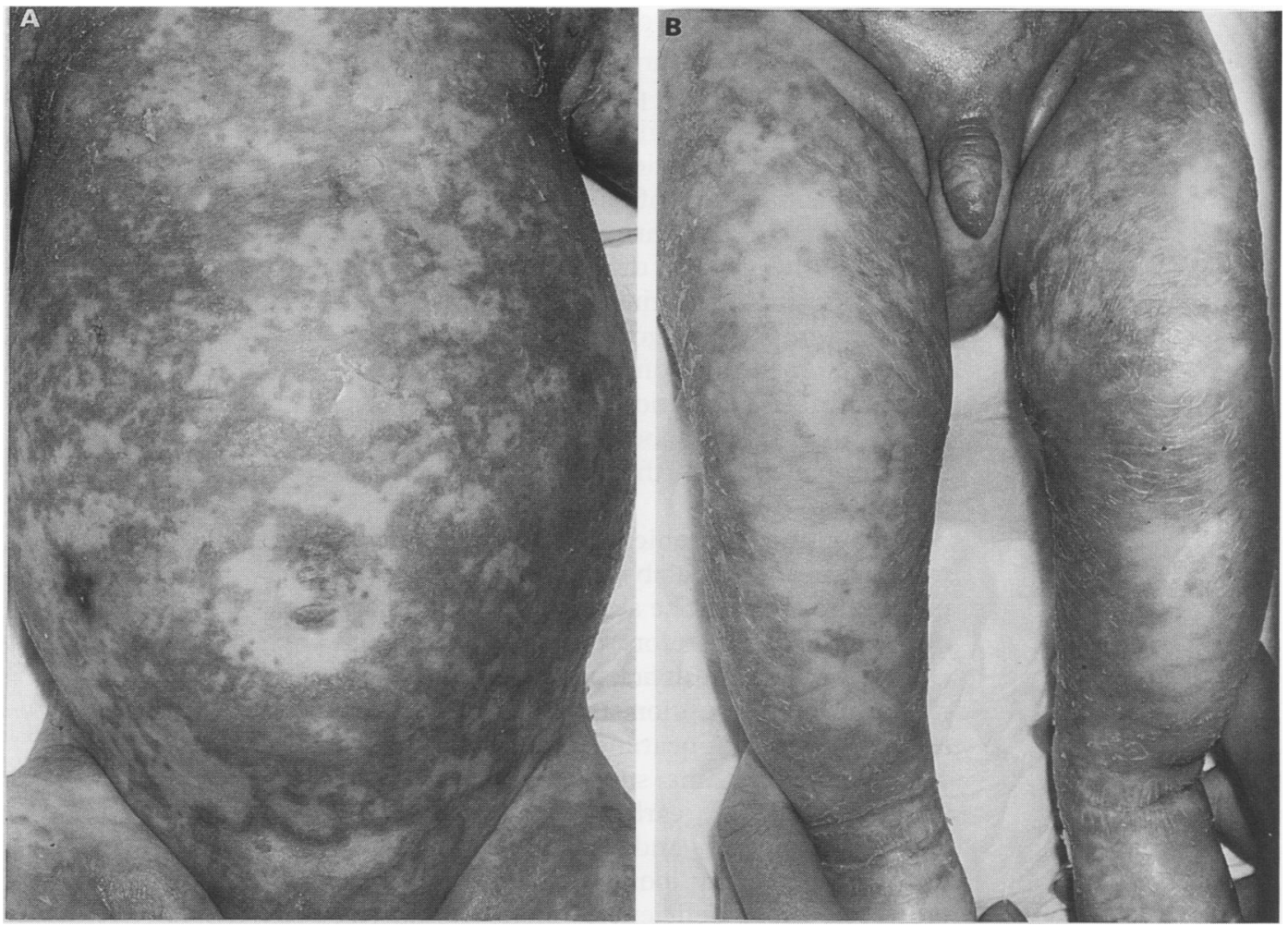

Confluent, desquamating erythematous rash seen on $(A)$ the trunk, and $(B)$ the legs of patient 1 at presentation, showing the reticulate distribution around islands of normal skin.

green but normal in consistency and volume. An erythematous papular rash appeared in the nappy area at 2 months of age and spread to involve her whole body over the next eight weeks. Worsening of the rash and associated failure to thrive led to her being admitted to hospital. Oral zinc and topical steroids led to some resolution of her rash but she developed a persistent fever despite oral antibiotics. At 5 months of age she was transferred to the Hospitals for Sick Children.

On examination she weighed $5 \mathrm{~kg}$ (below 3 rd centile) and was lethargic, with generalised oedema and a palpable liver edge $4 \mathrm{~cm}$ below the costal margin. A papular eruption was present on her trunk and limbs. It had become confluent on the buttocks and lower legs leading to erythematous, well demarcated, desquamative plaques similar in appearance to those seen in patient 1 . Her hair was sparse. Mucous membranes were unaffected.

Laboratory abnormalities included the following (normal range in parentheses): haemoglobin concentration $63 \mathrm{~g} / 1$ (105-135), prothrombin time 16 seconds (12-15), KPTT 43 seconds (30-40), aspartate transaminase 79 $\mathrm{U} / 1$ (20-60), albumin $19 \mathrm{~g} / \mathrm{l}$ falling to 8 (35-55), zinc $5.5 \mu \mathrm{mol} / 1$ (11-24), copper 7 $\mu \mathrm{mol} / \mathrm{l}(13-27)$, ferritin $330 \mathrm{mg} / \mathrm{l}(7-150)$, and low concentrations of many plasma amino acids. A liver biopsy specimen showed striking fat infiltration with a mainly periportal distribution, a mild periportal inflammatory reaction, some intrahepatocytic and perivenular bile pigment retention, and periportal accumulation of iron. Bone marrow aspirate and trephine showed marked dyserythropoiesis with vacuolated cytoplasm, normal megakaryocytes and myelopoiesis, and increased iron. Duodenal aspirate for pancreatic function tests showed absent lipase and trypsin before and after stimulation with cholecystokinin and secretin. Repeated sweat tests were technically unsatisfactory or gave inconsistent results.

A provisional diagnosis of the mitochondrial DNA deletion disorder, Pearson's marrow pancreas syndrome, ${ }^{5}$ was made based on the abnormal pancreatic function, the anaemia, and the vacuolated erythroblasts seen on marrow examination. After commencement of an elemental formula (Pregestimil) and zinc, vitamin and pancreatic enzyme supplements, her rash resolved. She lost weight as her oedema cleared, but subsequently gained weight satisfactorily. One year after discharge there had been no recurrence of her symptoms nor any evidence of chest disease. During this period of follow up, analysis of mitochondrial DNA for large deletions was normal (excluding Pearson's syndrome) and a diagnosis of cystic fibrosis was eventually reached when genetic analysis for cystic fibrosis mutations showed homozygous delta $F_{508}$ deletions on chromosome 7 . When her skin was normal, sweat sodium concentrations ( $\mathrm{mg}$ of sweat in sample) were found to be 93 (203), 104 (247), and 108 (269) $\mathrm{mmol} / \mathrm{l}$ respectively on three tests.

\section{Discussion}

These two patients both presented with a severe erythematous rash associated with lethargy, anaemia, generalised oedema, and severe hypoalbuminaemia. Although these latter findings are well recognised in cystic fibrosis, ${ }^{1-9}$ presentation with a rash is rare, having been reported in only nine infants. ${ }^{1-4}$ In each case where a description was given, the infants had generalised desquamative rashes similar to those in our patients. ${ }^{2-4}$ Diagnosis 
was typically delayed for several months, not only because of the rarity of the presentation, but also because the presence of oedema is associated with false negative sweat tests, as seen in our second patient. ${ }^{16-8}$

The identification of the mutations carried by our infants represents the first report of the nature of the genetic defect in children with cystic fibrosis presenting with a rash. Both infants were homozygous for the delta $F_{508}$ mutation on chromosome 7 , the most common cystic fibrosis mutation. Homozygosity for delta $F_{508}$ is seen in about two thirds of cystic fibrosis patients in the northern European population.

The clinical problems in these infants were caused by malabsorption secondary to pancreatic failure. The search for the aetiology of the rash has therefore focused on zinc and essential fatty acid deficiency as each of these can cause an eruption in which individual lesions have an appearance similar to that in our patients. ${ }^{2-4}$ Zinc supplementation is the likely cause of the early improvement in the rash in patient 1 and deficiencies of both nutrients probably contribute to the rash. However, these deficiencies alone would not give the clinical picture seen here.

More insight into the aetiology of the rash can be gained by comparing these infants with children who develop kwashiorkor secondary to poor nutrient intake. The cardinal features of kwashiorkor are oedema, lethargy, failure to thrive, hypoalbuminaemia, fatty liver, anaemia and a generalised, desquamative, erythematous rash. ${ }^{10-13}$ These are the same as the presenting features of our infants who also demonstrated other features of kwashiorkor such as sparse hair, lack of involvement of mucous membranes, raised hepatic enzymes, low serum concentrations of trace metals and raised ferritin concentrations. It is therefore reasonable to consider that our two patients have kwashiorkor secondary to malabsorption. The traditional view that kwashiorkor is caused by protein deficiency and that the oedema is secondary to the low serum albumin ${ }^{44-17}$ has been shown to be incorrect. ${ }^{11}{ }^{18-24}$ Golden et al have shown that, in a child with malnutrition, many factors, including multiple nutritional deficiencies, sepsis, viral infections, infestations and toxins, may act via a common mechanism of free radical damage to cause kwashiorkor. 112021 The free radical damage particularly affects mitochondrial and lipid membranes, leading to dysfunction of liver, marrow, skin, and fluid homoeostasis. Therapeutic measures aimed at minimising free radical damage may therefore lower the considerable morbidity and mortality seen with this presentation of cystic fibrosis. These measures include early supplementation with vitamins, potassium and trace metals including zinc, copper, and manganese. ${ }^{1012212526}$ Iron chelation treatment during the acute phase may also be beneficial, as there is evidence that the increased iron concentrations in kwashiorkor play a major part in free radical production. ${ }^{101121}$ The mainstay of management, however, remains the restoration of adequate nutritional absorption via elemental formulas and pancreatic enzyme supplements, coupled with aggressive antibiotic treatment and meticulous attention to fluid balance.

We are grateful to Dr Barbara Golden, University of Aberdeen, for much helpful discussion.

1 Abman SH, Accurso FJ, Bowman CM. Persistent morbidity and mortality of protein calorie malnutrition in young infants with CF. $₹$ Pediatr Gastroenterol Nutr 1986; 5: infants

2 Hansen RC, Lemen R, Revsin B. Cystic fibrosis manifesting with acrodermatitis enteropathica-like eruption. Arch Dermatol 1983; 119: 51-5.

3 Rosenblum JL, Schweitzer J, Kissane JM, Cooper TW. Failure to thrive presenting with an unusual skin rash. f Pediatr 1985; 107: 149-53.

4 Darmstadt GL, Schmidt CP, Wechsler DS, Tunnessen WW, Rosenstein BJ. Dermatitis as a presenting sign of cystic fibrosis. Arch Dermatol 1992; 128: 1358-64.

5 Rotig A, Cormier V, Blanche S, et al. Pearson's marrowpancreas syndrome: a multi-system mitochondrial dispancreas syndrome: a multi-system mitochondrin

6 Fleischer DS, DiGeorge AM, Barness LA, Cornfield D. Hypoproteinemia and edema in infants with cystic fibrosis of the pancreas. F Pediatr 1964; 64: 341-8.

7 Lee PA, Roloff DW, Howatt WF. Hypoalbuminemia and anemia in infants with cystic fibrosis. $\mathscr{F} A M A 1974 ; 228$ : 585-8.

8 Nielsen $\mathrm{OH}$, Larsen BF. The incidence of anemia, hypoalbuminemia and edema in infants as presenting symptoms of cystic fibrosis: a retrospective survey of the frequency of this symptom complex in 130 patients with cystic fibrosis. $\mathcal{F}$ Pediatr Gastroenterol Nutr 1982; 1 : w55-9.

9 Abman SH, Accurso FJ, Sokol RJ. Hypoalbuminemia in young infants with cystic fibrosis. $\mathcal{f}$ Pediatr 1990; 116: $840-1$

10 Golden BE. Primary protein-energy malnutrition. In: Garrow J, James WPT, eds. Human nutrition and dietetics. Edinburgh: Churchill-Livingstone (in press).

11 Golden MHN, Ramdath DD, Golden BE. Free radicals and malnutrition. In: Dreosti E, ed. Trace elements, micronutrients and free radicals. Totowa, NJ: Humana, 1991: 199-222.

12 Golden MHN, Golden BE, Bennett Fl. Relationship of trace element deficiencies to malnutrition. In: Chandra RK, ed. Trace elements in nutrition of children. New York: Vevey/Raven, 1985: 185-207.

13 Trowell HC, Davies JNP, Dean RFA. Kwashiorkor. $B M \mathcal{F}$ 1952; ii: 798-801.

14 Adams EB. Anemia associated with protein deficiency. Semin Hematol 1970; 7: 55-6.

15 Weil WB. Specific dietary needs. In: Rudolph AM, ed. Pediatrics. 18th Ed. Connecticut: Appleton and Lange, 1987: 169.

16 Barness LA. Nutrition and nutritional disorders. In: Behrman RE, ed. Nelson textbook of pediatrics. 14th Ed. Philadelphia: WB Saunders, 1992: 130-1.

17 Baritrop D. Nutrition. In: Campbell AGM, McIntosh N, eds. Forfar and Arneil's textbook of paediatrics. 4th Ed.

18 Golden MHN, Golden BE. Jackson AA. Albumin and nutritional oedema. Lancet 1980; i: 114-6.

19 Golden MHN. Protein deficiency, energy deficiency and the oedema of malnutrition. Lancet 1982; i: 1261-5.

20 Golden MHN. The consequences of protein deficiency in man and its relationship to the features of kwashiorkor. In: Blaxter K, Waterlow JC, eds. Nutrition adaptation in man. London: Applied Science Publishers 1985: 169-87.

21 Golden MHN, Ramdath D. Free radicals in the pathogenesis of kwashiorkpr. Proc Nutr Soc 1987; 46: 53-68.

22 Landman J, Jackson AA. The role of protein deficiency in the aetiology of kwashiorkor. West Indian Med $\mathcal{F} 1980 ; 29$ : 229-38.

23 Golden MHN. Transport proteins as indices of protein status. Am f Clin Nutr 1982; 35: 1159-65.

24 Gopalan C. Protein versus calories in the treatment of protein-calorie malnutrition: metabolic and population protein-calorie malnutrition: metabolic and population studies in India. In: Olson RE, ed. Protein-calori

25 Golden MHN, Golden BE, Harland PSEG, Jackson AA. Zinc and immunocompetence in protein-energy malnutriZinc and immunocompetence
tion. Lancet 1978; i: $1226-8$.

26 Golden MHN, Golden BE, Jackson AA. Skin breakdown in kwashiorkor responds to zinc. Lancet 1980; i: 1256. 